\title{
Electrification using Decentralized Micro Hydropower Plants in North-eastern Afghanistan
}

\author{
Ramchandra Bhandari $^{* 1}$, Anita Richter ${ }^{2}$, Andre Möller ${ }^{3}$, Rolf.-P. Oswianoski ${ }^{4}$ \\ ${ }^{1}$ Institute for Technology and Resources Management in the Tropics and Subtropics, \\ Cologne University of Applied Sciences, \\ Betzdorfer Strasse 2, 50679 Cologne, Germany \\ e-mail: bhandariramchandra@yahoo.com \\ ${ }^{2}$ Deutsche Gesellschaft für Internationale Zusammenarbeit (GIZ) GmbH, \\ Potsdamer Platz 10, 10785 Berlin, Germany \\ ${ }^{3}$ Alteburger Strasse 109, 50678 Cologne, Germany \\ ${ }^{4}$ Virtu Consult UG, Handjerystraße 94, 12159 Berlin, Germany
}

Cite as: Bhandari, R., Richter, A., Möller, A., Oswianoski, R.-P., Electrification using Decentralized Micro Hydropower Plants in North-eastern Afghanistan, J. sustain. dev. energy water environ. syst., 3(1), pp 49-65, 2015, DOI: http://dx.doi.org/10.13044/j.sdewes.2015.03.0004

\begin{abstract}
Electricity supply database from the Afghan national authority for electricity supply shows that about only $20 \%$ of the population in Afghanistan had access to grid electricity by 2010 . The national utility has a total capacity of about $842 \mathrm{MW}$, out of which about 696 MW was operational. Additionally, many decentralized units (Micro Hydropower (MHP) plants, diesel generators and solar home systems) supply electricity to about 7\% of the population. The donors supported National Solidarity Programme (NSP) has promoted hundreds of rural electrification projects. MHP plants are the major renewable energy based projects among them. In order to identify the operational status of installed MHP plants in four North-eastern provinces (i.e. Badakhshan, Baghlan, Balkh and Takhar) and to assess their socio-economic impacts, an extensive field monitoring had been carried out. The major parameters studied were spatial distribution of MHP plants, investment costs, operational models, end user electricity tariffs, productive use of electricity, community satisfaction, etc. Altogether, 421 MHP installations (about 11 MW installed capacity) were visited. The outcomes obtained from those surveys are presented in detail in this paper.
\end{abstract}

\section{KEYWORDS}

Electricity supply, Field survey, Hydropower, Renewable energy, Rural electrification, Productive use.

\section{BACKGROUND}

Energy is one of the basic inputs for all economic activity. Per capita energy consumption is one of the major determinants as well as an indicator of economic development. Per capita energy consumption and economic growth reinforce each other [1-3]. Access to modern energy, particularly to electricity, cuts across all sectors in rural development. Although access to electricity is not an end in itself, it is an essential tool to facilitate social and economic activity [4].

Grid electricity is available mainly in the big cities in Afghanistan. Most of this supply comes from imports, while the rest is generated within the country from hydro and thermal (diesel) resources. By 2010, the country had about 842 MW installed capacity.

\footnotetext{
* Corresponding author
} 
Out of this, about $696 \mathrm{MW}$ was reported to be operational [5]. In 2011, about 3,086 GWh electricity was supplied by the national utility "Da Afghanestan Breshna Sherkat (DABS)" in the country. The share of grid electricity supply by source types in 2010 2011 is given in Table 1 .

Table 1. Electricity generation in Afghanistan by source types in 2010-11 [6, 7]

\begin{tabular}{ccccc}
\hline Source types & $2010[\mathrm{GWh}]$ & 2010 share [\%] & 2011 [GWh] & 2011 share [\%] \\
\hline Hydro & 909 & 35.2 & 802 & 26 \\
Thermal (diesel) & 101 & 3.9 & 40 & 1.3 \\
Import & 1,574 & 60.9 & 2,244 & 72.7 \\
Total & 2,586 & 100 & 3,086 & 100 \\
\hline
\end{tabular}

As shown in Table 1, the country depends largely on imported electricity from its neighbours (mainly from Turkmenistan, Tajikistan, Uzbekistan and Iran). Hydropower is the major source for inland electricity generation. Thermal generation is mainly based on imported diesel. The share of other renewable energies (e.g. solar, wind, biomass, etc.) for electricity supply is negligible.

According to the Afghan Central Statistics Organization (CSO) [8] estimate, the total population of the country (in its 34 provinces) was around 24 million in 2009/10. About $76 \%$ of this population lives in rural areas [9], mostly without access to modern form of energy. Table 2 shows the DABS customer numbers under different user categories from 2006 to 2010 throughout the country.

Table 2. Numbers of DABS customers (connections) in Afghanistan [10]

\begin{tabular}{cccccc}
\hline Year & 2006 & 2007 & 2008 & 2009 & 2010 \\
\hline Residential & 391,683 & 502,856 & 574,379 & 671,266 & 682,454 \\
Commercial & 30,888 & 39,811 & 47,139 & 56,803 & 58,381 \\
Government & 3,187 & 4,208 & 4,950 & 4,153 & 4,191 \\
Holy places & 4,449 & 2,699 & 3,941 & 5,788 & 5,921 \\
Industrial & 2,399 & 1,688 & 2,620 & 1,912 & 1,860 \\
\hline
\end{tabular}

Not surprisingly, the residential customers overshadow the other customer groups. The specific information on the amount of electricity consumed by each group was not available. An unofficial estimate from the DABS implied that about $80 \%$ of the sold electricity is consumed in residential sector, about $10 \%$ in industrial sector and the rest $10 \%$ in other sectors. Assuming an average of 7 people per customer (household) in residential sector [11], it can be said that about $20 \%$ of the country's population was supplied with the grid electricity in 2010. Additionally, an estimated $12 \%$ of the rural population in the country would have access to electricity, provided all the installations under National Solidarity Programme (NSP) would have been operational (Figure 1). The rest of the population depends heavily on kerosene lamps and fuel wood for lighting and on diesel for operation of agricultural machinery such as flour grinding mills, etc. Direct burning of biomass (agricultural residues and fuel wood) is the major source for cooking and space heating energy needs. The households and commercial entities connected to the grid do not have a reliable supply. Scheduled load shedding and unscheduled blackout is common. No official data could be obtained from DABS regarding the average power-cut hours in a year, however, the residents reported it to be about 4-6 hours a day. 
Private sector development in the area of rural electrification through renewable energies is still weak in the country. Security risks for investment and low electricity demand as well as purchasing power of the rural population are two of many reasons. At present, the rural electrification through renewable energy strongly relies on government and foreign donor supports. Due to factors such as rough terrain, extreme remoteness, high investment costs, etc. among many others, the national grid extension throughout the country is very unlikely in the foreseeable future. Therefore, off grid alternatives offer a more realistic option when it comes to increasing the coverage of electricity access in developing regions [12]. Further installations and proper monitoring of the isolated power generation systems, e.g. MHP plants and solar home systems (SHSs), could contribute to the electricity supply to rural folks.

There are significant numbers of smaller projects implemented for rural electrification in Afghanistan (mainly under the NSP). The sustainability of any rural electrification project requires active local participation in development and implementation of such projects [13]. The NSP serves this purpose. It is a nationwide rural development program first established in 2003. The program states its goal as to develop the ability of Afghan communities to identify, plan, manage and monitor their own development projects [14]. The program's main objective is the establishment of community development councils (CDCs) to function as institutions for local governance leading the social and economic developments in their communities. The CDCs lead national efforts for local governance, rural development and poverty alleviation in their communities [15].

As of December 2010, there were as many as 51,870 projects implemented under the program with a total cost of USD 750 million [16]. They include both infrastructure projects such as water and sanitation, power, irrigation, transport, and education as well as social projects like vocational training and literacy courses. Energy sector is an important component of the program and there were as many as 6,680 energy projects with a total cost of USD 148 million implemented under this program [16]. Renewable energy based rural electrification projects implemented under NSP include small wind turbines, MHP plants, SHSs, etc. [15]. In the past diesel generators were also promoted intensively; however, NSP does not support diesel plants anymore. The capacity installed under NSP using hydro, thermal (diesel) and solar resources in individual provinces of the country is given in Figure 1.

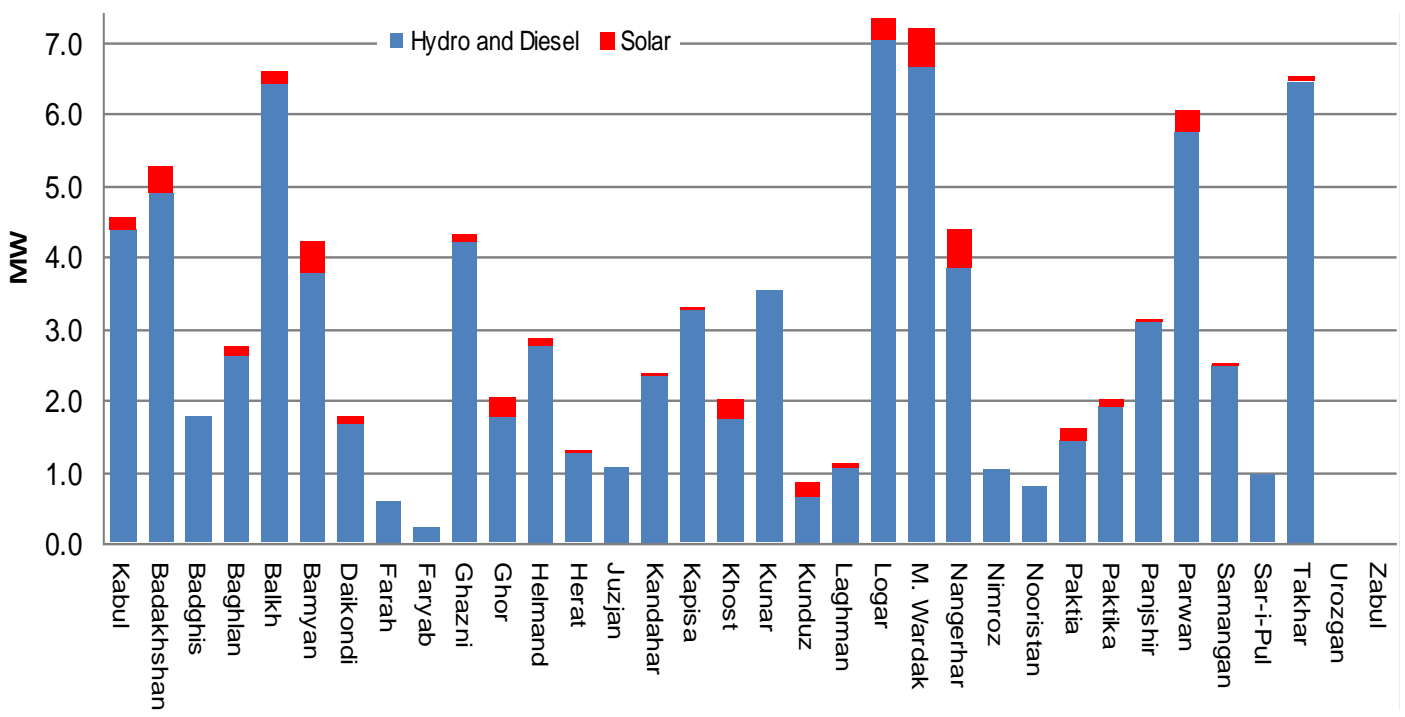

Figure 1. NSP installed capacity in Afghan provinces during 2005-2010 [17] 
The total installed capacity under NSP between 2005 and 2010 was reported to be about $93 \mathrm{MW}$, which consist of about $28 \mathrm{MW}$ from hydropower, about $58 \mathrm{MW}$ from diesel and about $7 \mathrm{MW}$ from solar energy [17]. The villagers have reported that many of the diesel generators and solar home systems installed under NSP are no longer operational. The authors have visited some SHS installations and found that most of the systems were out of use after two years from installation. The lead acid battery was not anymore functional and there was no battery replacement mechanism in place. High diesel prices, faulty installations and no equipment replacements (diesel engine and solar batteries) are the most common reasons cited. Also some of the MHP plants are not in proper operation. Estimate from different stakeholders lies between 20 and $40 \%$ (e.g. [18]) for non operational hydro capacity.

Besides the decentralized power supply projects, there is a transmission line project under implementation. The North East Power Supply (NEPS) program, a major transmission grid project in the country, is under construction to provide power to the north-eastern portion of Afghanistan, including Kabul. The infrastructure will help to import power from neighboring Tajikistan, Turkmenistan and Uzbekistan at significantly lower cost than diesel powered sources of electricity. For the isolated regions, the government further plans to implement off-grid systems based on renewable energy as mentioned in its national development strategy.

The main objective of this paper is to identify the status of MHP plants that were installed mainly under NSP in four North-eastern provinces of the country: Badakhshan, Baghlan, Balkh and Takhar (marked with solid-red borders in Figure 2) by carrying out the field monitoring of individual sites and to assess their socio economic impacts. Those survey outcomes mainly include - numbers of surveyed MHPs in individual province, MHP plants installation years, capacity range of individual MHP plant, turbine types, initial investment cost in USD/kW, project implementing agency (donor/private/government), daily MHP plant operation schedule, end user tariffs, productive use of the electricity, and the end user's satisfaction to the electricity supply. Results obtained thus, together with the information about other means of electricity generation and supply systems in these provinces and in a country as a whole, are expected to be an important dataset in order to develop a provincial and national electrification plan for different stakeholders.

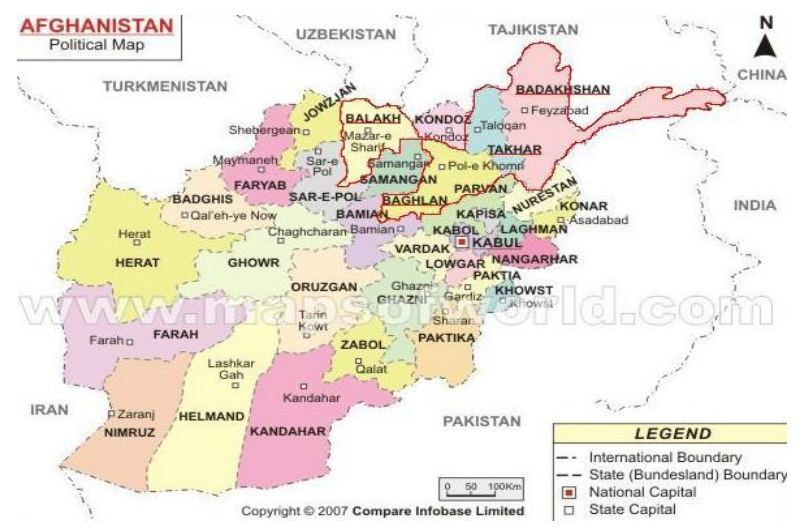

Figure 2. Four studied provinces in the North-eastern Afghanistan (enclosed by solid border) Source: www.mapsoftheworld.com

\section{FIELD MONITORING}

This paper limits its scope of analysis only in these four provinces mentioned above and only to the MHP plants. The questionnaires were developed by the authors or under 
the direct supervision of the authors. For the survey, qualified local electrical engineers were hired and sent to the villages with necessary knowledge and equipment. They were trained on the data collection and field monitoring procedure before they went to the fields. Authors of this paper could not visit the individual MHP installation sites themselves (except a few sites located nearby from the provincial capitals) due to local political and security concerns. However, they were in contact with the surveyors via phone whenever communication was necessary to ensure the accuracy and quality of the gathered information.

The survey questionnaire comprised altogether 47 points. Selected major points in the questionnaire included: date of survey; name of project site, village, district and province; name of CDC responsible for plant operation; number of families/houses/people supplied with the electricity; start and end year of plant construction; available water flow in the river; condition of civil infrastructure such as weir, forebay tank, spillway, settling basin, flushing gate, etc.; manufacturer, type, nominal capacity and number of turbines at the site; generator type and its rated capacity; initial project costs and the project implementing agency; plant operation hours in a day; operation model and operator's salary; electricity tariffs; productive use of electricity; end user's overall satisfaction with the electricity supply; and additional open comments from the informants. In most of the surveyed sites, photographs of river and canal intake, other civil components and powerhouse components (turbines, generators, etc.) were taken by the surveyors to support the data analysis afterwards.

\section{Study area}

This section gives a short overview of the four provinces studied. Badakhshan province is bordered by Takhar province in the west and Nuristan in the south (Figure 2). It shares international borders with Tajikistan in the north, China in the east, and Pakistan in the southeast. The province has 28 administrative districts. The province is home to about 860,300 people [8] and the provincial capital is Faizabad. The national electricity transmission and distribution grid does not link this province. Altogether $173 \mathrm{MHP}$ plants distributed in 24 districts (out of 28 districts) of this province were visited during 2008-2010.

Baghlan province is bordered by five provinces: Parwan, Bamyan, Samangan, Kunduz and Takhar (Figure 2). It is divided into 15 administrative districts. The provincial capital is Pul-i-Khumri. The province is home to about 818,600 people [8]. The national grid passes through this province and the provincial capital has access to electricity. However, only about $9.5 \%$ of the province's population has access to the grid electricity [10]. In this province, the field survey was carried out in 2010 in its 5 districts and altogether 58 MHP plants were visited.

Balkh province is bordered by four provinces: Kunduz, Samangan, Sar-i-Pul and Jawzjan (Figure 2). It is divided into 15 administrative districts. The provincial capital is Mazar-i-Sharif. The province is home to about 1,169.000 people [8]. The national grid passes through this province and the provincial capital has access to grid electricity. In 2010 , about $46 \%$ of the province's population was said to be supplied with grid electricity [10]. The survey was carried out in 2010 in 3 districts and altogether 15 sites were visited.

Takhar province has 17 administrative districts and its provincial capital is Taloqan. The province is home to about 886,400 people [8]. The national electricity grid does not link this province so far. The survey was carried out in 2009 in 11 districts and altogether 175 sites were visited. About $1.3 \%$ of the province's population living in Taloqan was supplied with diesel electricity from DABS in 2010. The electricity tariff was $66 \phi / \mathrm{kWh}$ for residential customers (USD $1=\sim$ AFN 53, Afghan afghani) [19]. This figure is quite 
higher than the DABS national grid average price of $11 \phi / \mathrm{kWh}$ for residential customers, e.g. in Kabul.

\section{RESULTS}

The monitoring results on the MHP plants installed in the studied four provinces are discussed in this section. Not all the MHP plants installed in those provinces had been visited because of different reasons (e.g. security, transportation, time constraints, etc.). The summary of the surveyed sites is given in Table 3 .

Table 3. Summary of MHPs survey results in four province

\begin{tabular}{ccc}
\hline Description & Unit & Value \\
\hline Total number of surveyed MHP plants & {$[$ Number $]$} & 421 \\
Total installed capacity (considered only in 406 sites) & {$[\mathrm{MW}]$} & 10.7 \\
Total operational capacity (out of 406 sites) & {$[\mathrm{MW}]$} & 7.6 \\
Average cost of installation (excluding Badakhshan) & {$[$ USD/kW] } & 2,291 \\
Total population to be supplied in 4 provinces & {$[$ People] } & $380,209(\sim 10 \%)$ \\
\hline
\end{tabular}

As can be calculated from Table 3 , about $71 \%$ of the installed capacity was operational in those four provinces. The MHP plants in only 332 sites were found in proper operational condition during the time of field visits. Among the non-operational sites, about 38 sites were under construction during the time of survey. For the rest of the sites, either no information was available or they were not operational due to some defects in their civil, mechanical or electrical components. The classified results obtained and analyzed from the field monitoring surveys of these MHP plants are described in the following sub-sections.

\section{Number of MHP plants surveyed}

Figure 3 shows the MHP plants installation in individual province. In Badakhshan, the MHP installations after 2009 are not included. In the other three provinces, the shown numbers include the installations until 2010. These numbers also include MHP plants, which were under construction during the time of the visit. In Baghlan, although initial plan was to visit about 108 sites in 10 districts (out of total 15 districts of the province), only 58 sites distributed in five districts could be visited, due to the volatile security concerns in this province compared to other three provinces. In Balkh, altogether 15 sites were visited in 3 districts (out of 15 districts). In comparison, the number of installed MHP plants is relatively small in Balkh, as the grid electricity is available in provincial capital and some other districts. In Takhar, 11 districts (out of 17) of the provinces were visited.

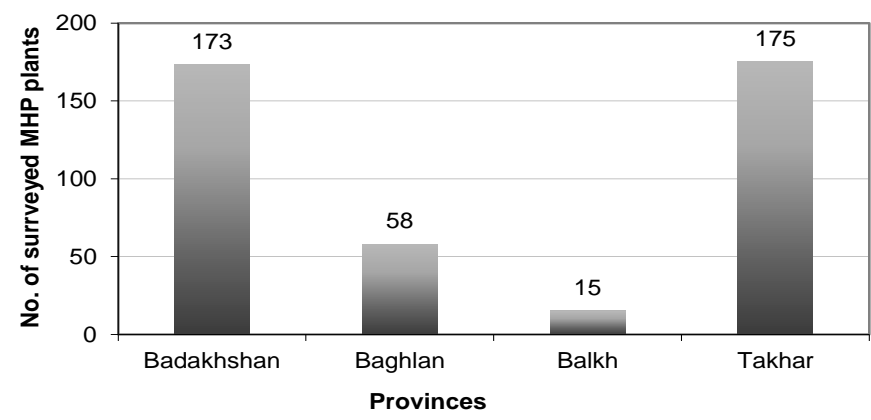

Figure 3. Surveyed numbers of MHP plants in each provinces 


\section{Installation years}

Figure 4 shows the MHP plant installations over different years. Despite the political instability, recent years have seen a higher growth rate for new installations. The higher numbers after 2005 are mainly due to the donors supported NSP. There was no correlation between the plant installation year and the operation condition of the plants, i.e. also the older plants were performing well, while in some cases the newer plants were out of operation.

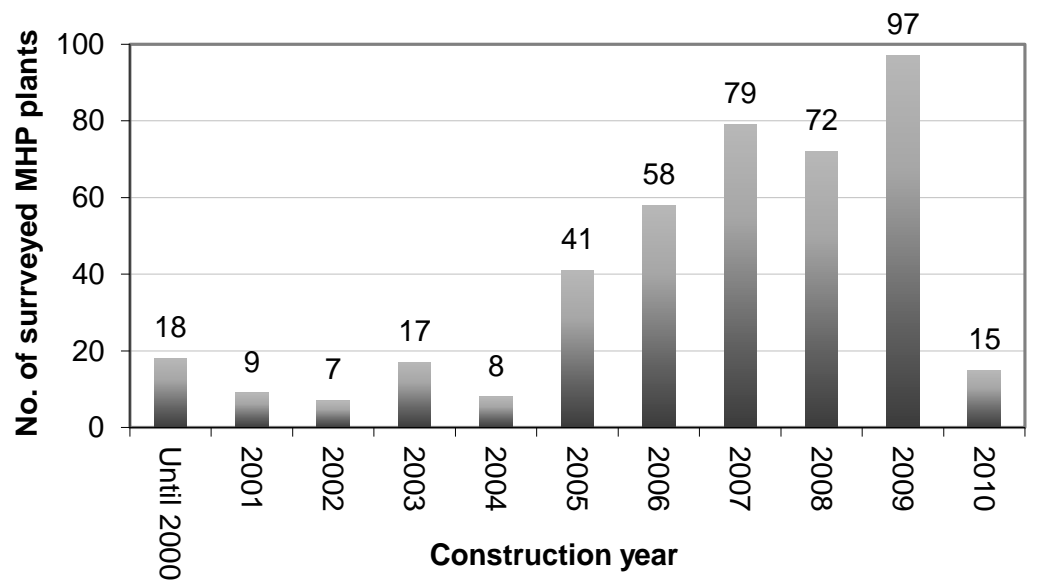

Figure 4. MHP plant installations over the years

\section{Ranges of installed capacity}

The survey team has collected data on the design capacity of individual power plants based on design reports. Most of the power plants operate during the night time, while the survey team visited the sites during the day time. This is why no immediate measurement of power output on the many sites could be made during the visit. It is difficult to say about the actual performance of these plants based on only information on nominal power output because the actual power output might differ largely in some cases. However, in this paper, the nominal design capacity of the turbines has been used in order to calculate the total installed capacity. The ranges of power plant capacities (nominal turbine capacity at individual site) in all four provinces are given in Figure 5.

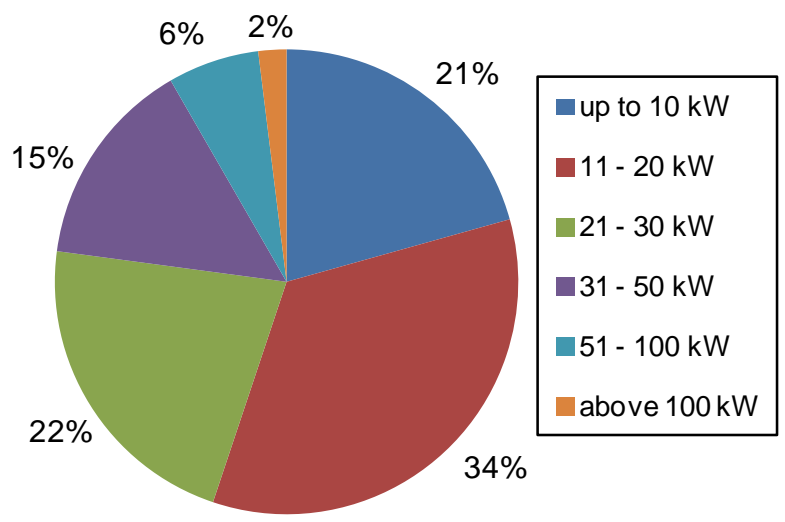

Figure 5. MHP plants according to their nominal installed capacity in $\mathrm{kW}$

In Badakhshan, altogether 173 MHP plants were surveyed with a total installed capacity of $5.18 \mathrm{MW}$ connecting to about $15 \%$ of the province's population. From the 
total installed capacity, only $57 \%$ of capacity (2.94 MW) was operational. In Baghlan, the total installed capacity has been calculated to be about $810 \mathrm{~kW}$ (in 58 sites). The plant capacity at individual sites varied from 5 to $30 \mathrm{~kW}$. In Balkh, the total installed capacity has been calculated to be only about $299 \mathrm{~kW}$ (in 15 sites), while the plant capacity at individual sites varied from 10 to $48 \mathrm{~kW}$. However, the total installed capacity of the operational power plants was only about $244 \mathrm{~kW}$ (in 13 sites). In Takhar, a total installed capacity of about $4.4 \mathrm{MW}$ (in 160 sites) was reported, where only about 3.9 MW (in 144 sites) was operational. The nominal capacity at individual sites varied from 4 to $152 \mathrm{~kW}$.

\section{Turbine types}

A large number of water wheels (82) are installed in Badakhshan. Additionally, there are 86 cross flow turbines, one Pelton turbine and three Francis turbines. In Baghlan and Balkh, all the sites that are operational use cross flow turbines. In Takhar, two sites use Francis turbines, 27 sites use water wheels and the majority of the sites (i.e. 129) are equipped with cross flow turbines, a popular turbine for small MHP plants in many other countries too. No information on turbine types was provided for the rest 17 sites in Takhar, stating some are under construction and no reason was mentioned for the others. One of the surveyed power plants (in Farkar district) had three cross flow turbines with a total installed capacity of about $152 \mathrm{~kW}$ (individual turbines of 54,54 and $44 \mathrm{~kW}$, respectively). Another 15 power plants had two cross flow turbines at each site and the remaining plants had only one turbine per site. Most of the cross flow turbines were manufactured within the country, mainly by the manufacturers located in Kabul. Figure 6 shows the turbine types. The term unknown in the figure refers to those MHP plants that were under construction.

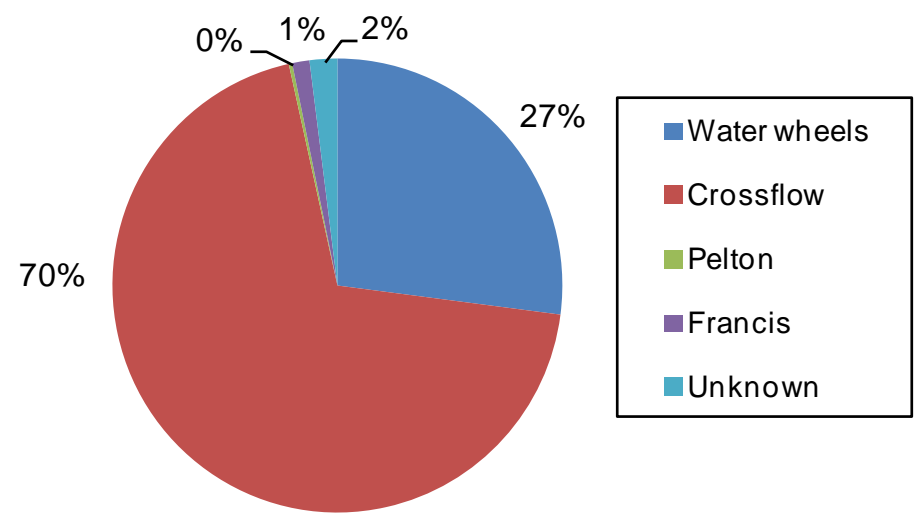

Figure 6. MHP plants according to their turbine types

\section{Investments}

Figure 7 shows the investment costs per unit installed capacity calculated for 215 surveyed sites in the provinces of Baghlan, Balkh and Takhar. No investment cost information was recorded for Badakhshan province. In Baghlan, about $83 \%$ of the installed capacity was more expensive than $2,500 \mathrm{USD} / \mathrm{kW}$, which is far above the investment costs for MHP plants in Takhar province. The reasons were most likely the volatile security situation compared to other studied provinces. In Balkh, about $34 \%$ of the installed capacity was cheaper than $2,000 \mathrm{USD} / \mathrm{kW}$ and about $74 \%$ of the capacity was below $3,000 \mathrm{USD} / \mathrm{kW}$. In Takhar, about $46 \%$ of the installed capacity was cheaper than $1,000 \mathrm{USD} / \mathrm{kW}$, which is far lower than the investment costs for other renewable energy sources e.g. solar PV. 


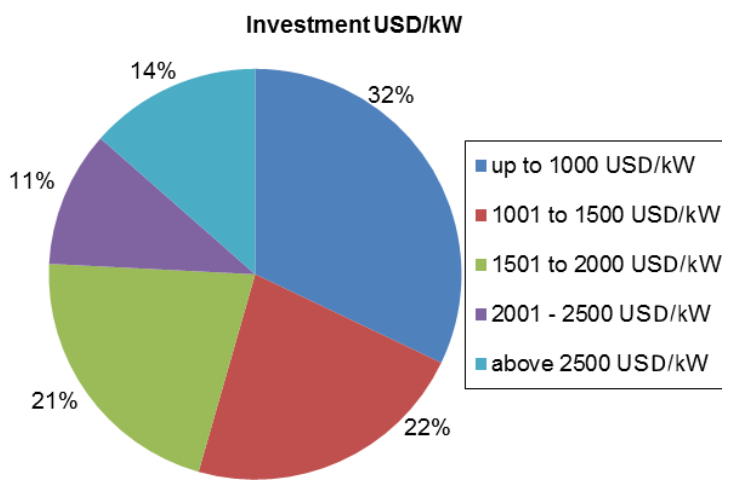

Figure 7. Share of MHP plants based on their initial investment cost in USD/kW

\section{Project implementation agency}

The majority of the projects were implemented jointly by community and NSP. In those sites, the community members basically support in construction work rather than cash payment. As a general rule, about $10 \%$ of the total investment cost is contributed by the community in NSP implemented projects. In Badakhshan, 81 units were installed under NSP, whereas as many as 90 units (mostly water wheels) were installed under private initiatives. Two of the units were implemented by DABS, each in Faizabad and Baharak. In Baghlan and Balkh, all the installations were under the NSP. In these two provinces, none of the units was installed under private initiatives unlike in Takhar and Badakhshan provinces. In Takhar, about $88 \%$ units were implemented under NSP. About $12 \%$ of the units were installed under private initiatives. One unit in Khwaja Ghar district (one cross flow turbine with an installed capacity of $36 \mathrm{~kW}$ ) was implemented by the energy program of then German Technical Cooperation (GTZ, present GIZ). Aggregated in four provinces, about $73 \%$ of the projects were implemented under NSP, $26 \%$ under private initiatives and only $1 \%$ under DABS.

\section{Plants operating time}

Figure 8 to 11 show the daily operating schedule for the surveyed power plants in all four provinces. In Badakhshan, only two plants were reported to be operational round the clock. The majority of the plants operate only during the night. In Baghlan, among 42 reported plants, almost all were operational throughout the night. Also in Balkh, among reported 15 units, most of the plants were operational throughout the night. In Takhar, almost $47 \%$ (out of 153 reported) plants were operational throughout the night. Only two units - one operated by private sector and the other by community - were generating electricity round the clock. Both of them were supplying electricity also for productive uses.

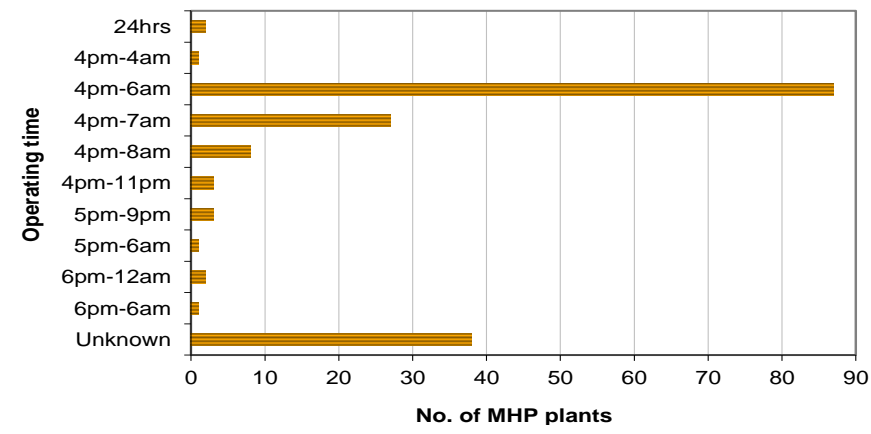

Figure 8. MHP plants operation time - Badakhshan 


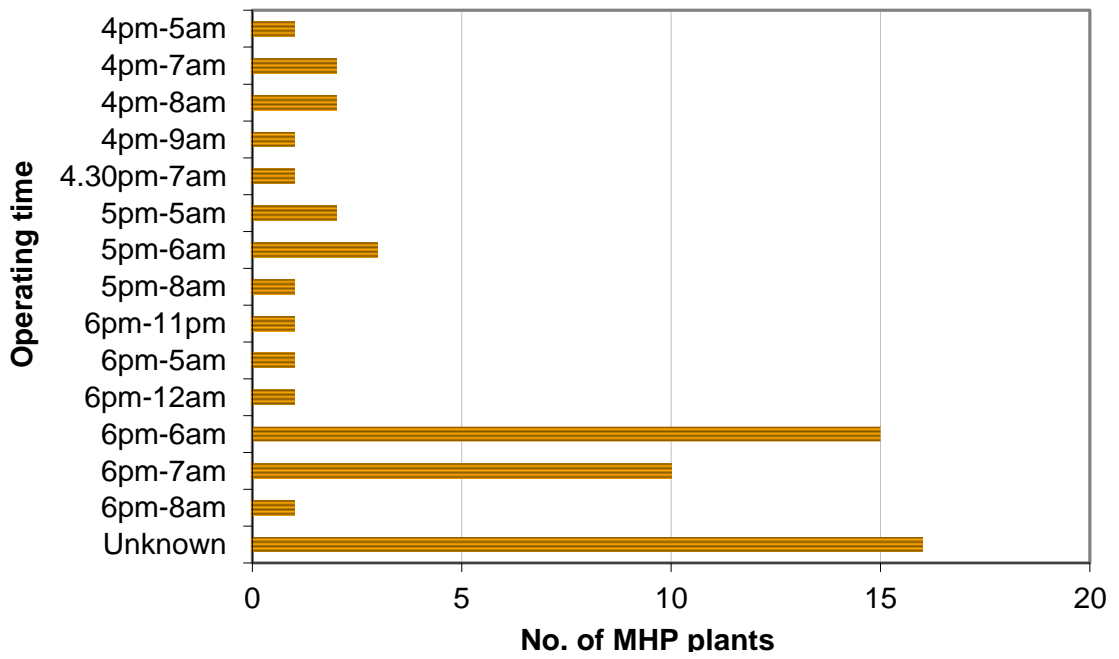

Figure 9. MHP plants operation time - Baghlan

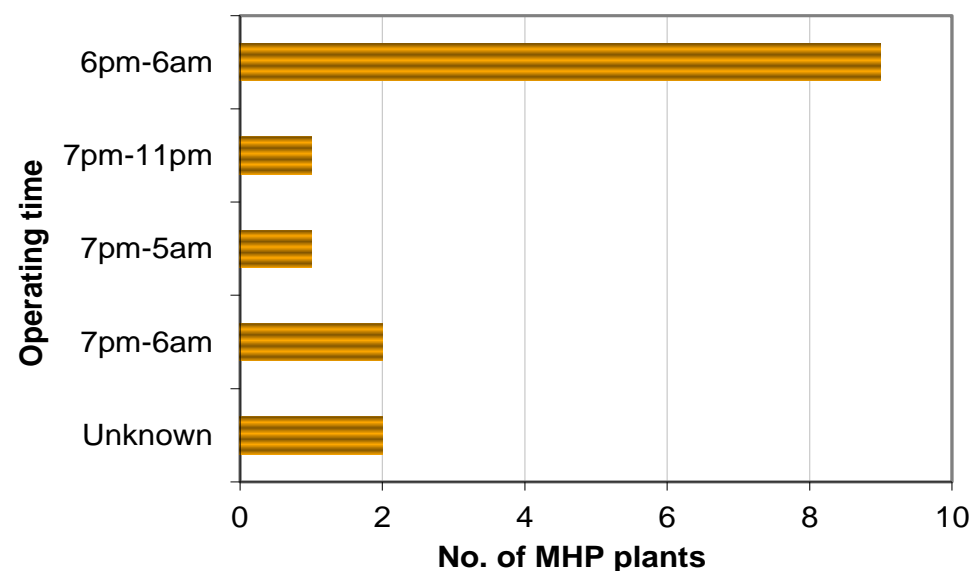

Figure 10. MHP plants operation time - Balkh

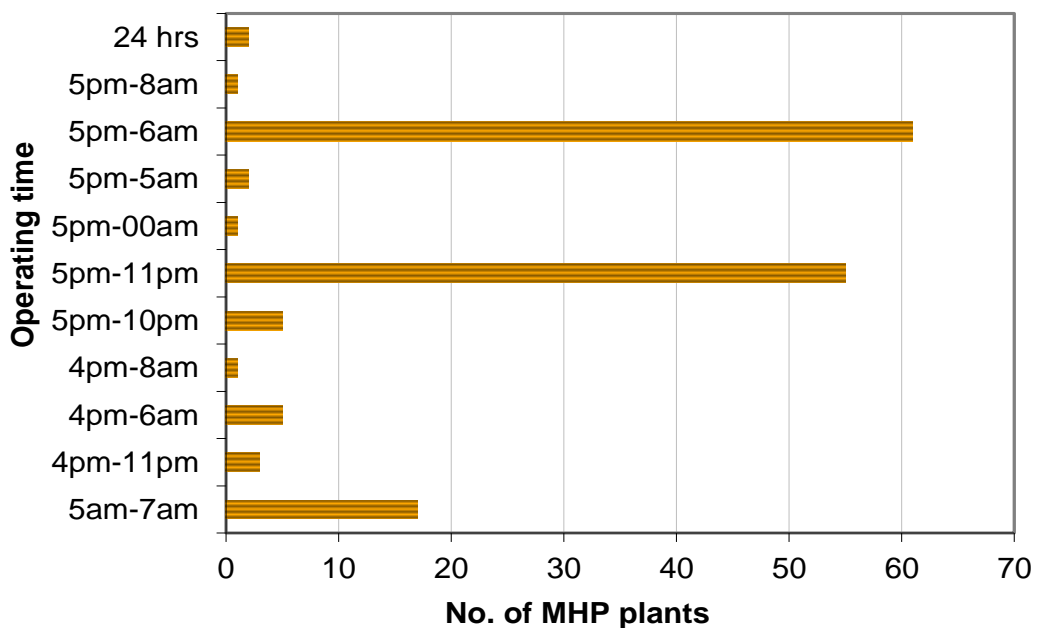

Figure 11. MHP plants operation time - Takhar

\section{End user tariff}

Figure 12 to 15 shows the end user electricity tariff (only for MHP plants) in four provinces. 


\section{Badakh Fee}

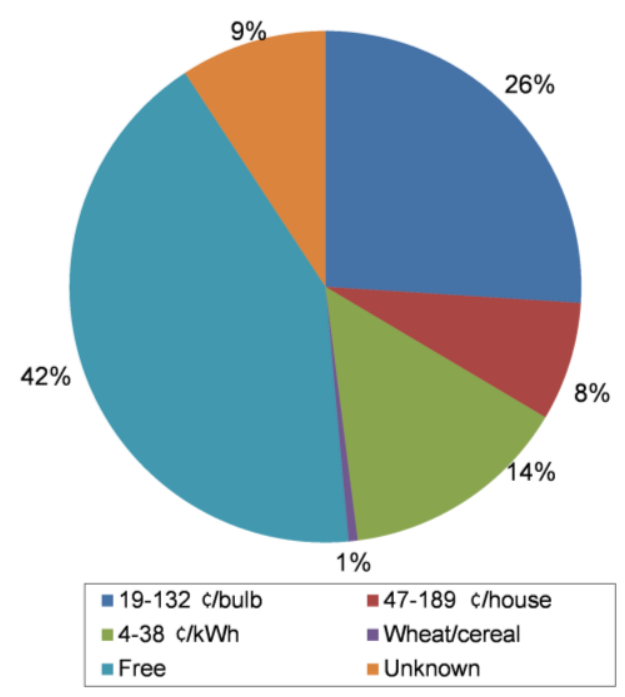

Figure 12. Electricity tariff for end users - Badakhshan

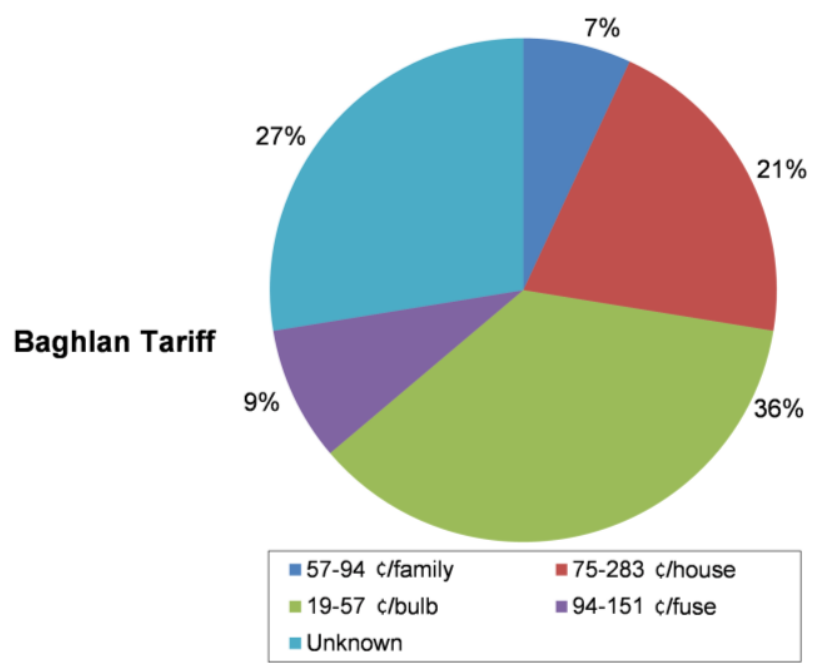

Figure 13. Electricity tariff for end users - Baghlan

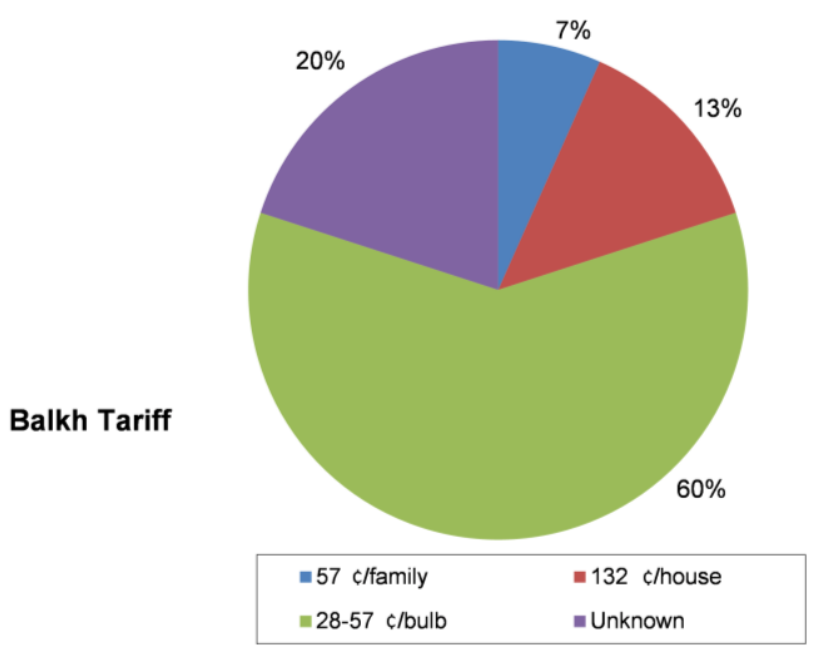

Figure 14. Electricity tariff for end users - Balkh 


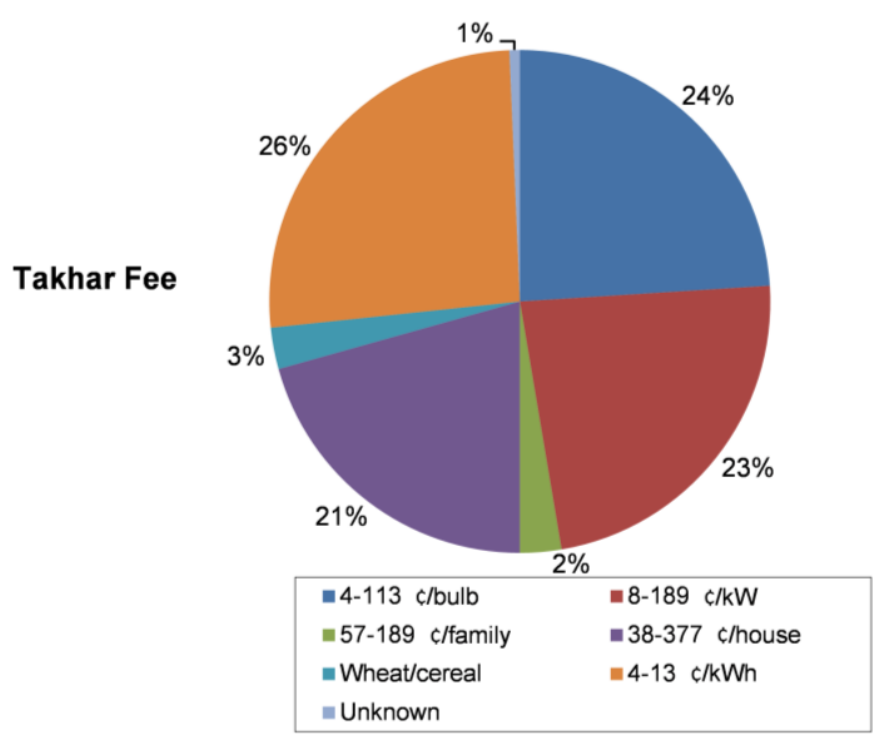

Figure 15. Electricity tariff for end users - Takhar

In Badakhshan, as many as 73 sites, mostly water wheels, offered the end users electricity or mechanical services free of cost. This certainly leads to problems with repair maintenance and thus it could be one of the reasons why the share of non-operational plants in this province is the highest. Other tariff structures were based on per bulb, or per house, or per $\mathrm{kWh}$, etc. as shown in Figure 12. In Baghlan, the electricity generated from these power plants was not sold to the consumers based on meter reading. Instead, different flat rate tariff structures have been adopted, such as per bulb, per house, per family, per fuse (with power consumption limit of 200 Watt), etc. A range of fee structure for Baghlan can be seen in Figure 13. In Balkh too, different flat rate fee structures had been adopted as given in Figure 14. In Takhar, the electricity generated from about one fourth of the power plants (out of 150 sites for which such information is available) was sold to the consumers based on meter reading (i.e. per $\mathrm{kWh}$ basis). In the remaining plants, different flat rate tariff structures had been adopted as can be seen in Figure 15.

\section{Productive use}

Productive use means utilizing the electrical (and/or mechanical) energy for promoting employment, income generation, adding value to marketable products or services, etc. The productive use strategy may include a number of elements: awareness raising at target group, business idea generation and training of potential or existing business persons, access to micro finance, technical and vocational training, marketing support, etc. Such a strategy needs to be supplemented by studies about socio-economic potentials for energy planning and supply in the regional scale [20]. In this section, the major productive uses in survey sites refer to flour mills, oil pressing mills, saw mill, metal workshop and carpentry. Figure 16 shows the share of MHP plants (in number of units) supplying electricity for productive use.

In Badakhshan, only three units were supplying electricity for productive use. At the rest of the sites, the electricity generated from these plants had been exclusively used for household consumption and none of these plants supplied electricity for machinery and other appliances that are used for income generation. In Baghlan and Balkh, none of the units contributed to productive use. One of the reasons behind it could be relatively small capacities of these power plants. In Takhar, each MHP plant was supplying electricity to 
a single machine that is used for entrepreneurial use in about 38 sites and each plant was supplying electricity to two machines used for productive use in another four sites. Also the power plants in about 11 additional sites were reported to have been supplying the electricity to productive users, though no elaboration has been made. No such information was recorded for about $15 \%$ of the sites.

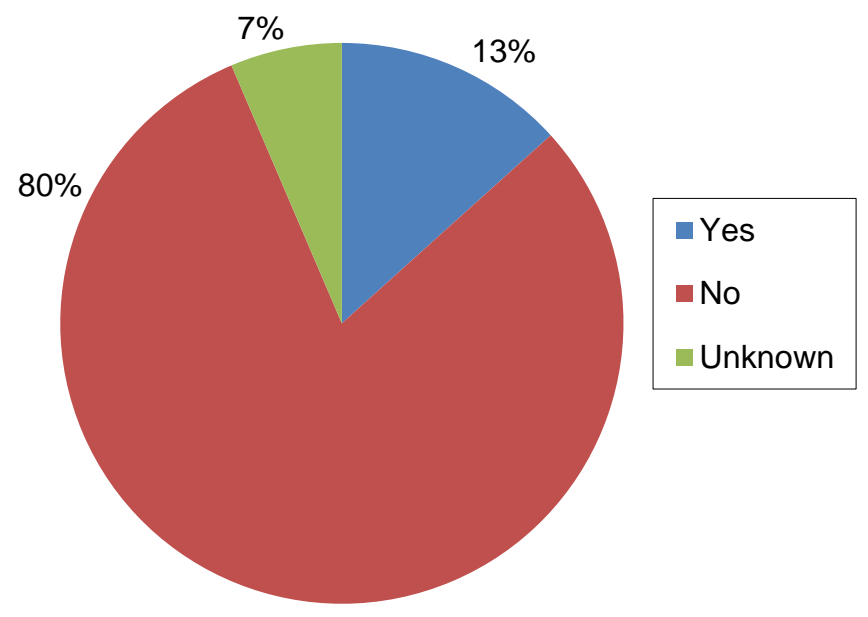

Figure 16. MHP plants supplying electricity also for productive use

\section{Community satisfaction}

By community satisfaction here is meant whether the end users get scheduled electricity supply without acute disruptions. In Badakhshan, the end users connected to 145 MHP plants were reported to be satisfied with the electricity supply. Those numbers for Baghlan and Balkh were at 41 and 10 sites, respectively. In Takhar, the end users connected to about 137 of the MHP units are reported to be satisfied with the use of electricity. The combined values for all four provinces show that the end users at about $79 \%$ of the sites were said to be satisfied, whereas $11 \%$ were said to be dissatisfied. For $10 \%$ of the sites, no response had been reported. Many reasons were mentioned for the cases of non-satisfaction, such as too many users were connected to a single supply system and the supply voltage was too low, power plants were not operating due to damage of certain parts, etc. Similarly, other reported common problems were leakage in canals, problems in intake and weir that were not made of concrete, etc. In some sites, during the flood season, intakes and weirs were swept away and villagers were without electricity for some days or weeks. However, it was also reported that the villagers repair such damages on their own; and therefore, the power plants could be operational again.

\section{SUMMARY}

The discussed survey gave an overview on the current status of the installed MHP plants in the four provinces studied. The following summary has been drawn from the monitoring:

- Almost $80 \%$ of the Afghan population still lack access to grid electricity supply. Decentralized power plants, mainly those based on hydro and solar resources, could play a vital role to supply these people with electricity;

- A significantly large number of rural electrification projects have been installed in the country, especially after 2005 under donor supported NSP programme. These projects, if all were operational, would supply the electricity needs of country's $7 \%$ population; 
- In the four provinces studied, the recent MHP plants installation is in increasing trend. The choice of installation sites is not necessarily based on the optimal match of the local demand for electricity and the on-site resources availability, sometimes they are based on other preferences (donor's interests, security issues, etc.). This is why relatively safe Badakhshan and Takhar provinces see significantly higher number of installations. Comparably easier access to grid in Balkh and Baghlan provinces are other reasons for fewer installations there;

- Most of the installed MHP units have nominal capacities below $50 \mathrm{~kW}$. Those small plants are mainly aimed to provide light to the end users. Therefore the consumption of electricity from such plants is relatively low and thereby less revenue. These plants may pose a financial problem once the plants need repair-maintenance work;

- Cross flow turbines are extensively used. The positive side of these types is that the domestic manufacturing (in Kabul) of these units ensures the repair-maintenance know-how in case of defects. Other countries, especially Nepal, have examples of technical success of installed MHP plants when the plant components are locally manufactured and installed;

- Investment cost for the installed plants varies in a large range, i.e. below 1,000 to above 2,500 USD/kW. The lower costs are difficult to justify; most likely they do not include the non-monetary community contribution in their calculation. The higher costs include extra expenses for transportation of the materials up to the project site and sometimes also security related expenses. The capacity costs for MHP plants in other countries are also in similar higher ranges, e.g. about 2,500-3,000 USD/kW for the plants in range of $50 \mathrm{~kW}$ [21]. The investment cost in the surveyed sites is mostly from the donors in the form of donations. For the sustainability of donor supported rural electrification projects, the end user's focus should be thus to cover the operational and maintenance costs;

- Most of the projects are implemented under NSP. Such projects are operated by the communities once the project is commissioned. The national authority responsible for the electricity supply in the country, DABS, has not been involved in those small projects;

- Most of the plants are not operated round the clock, as there is no demand for electricity. Most of the plants supply electricity for lighting. The revenue from the power plants depends on the electricity sales, thus idling the plants most of the time is not economically sound. Additional entrepreneurial demand should be created for the electricity to ensure the necessary repair maintenance of the plants whenever necessary as well as to boost the local economy;

- Different end user tariffs have been set, from flat rate basis to consumption basis (meter reading). Non monetary tariffs are also common, adjusted to the local socio-economic situation of the end users. One of the reasons for relatively small share of meter based tariffs is also due to additional meter costs. Once the demand for electricity could be increased, the use of meters could be promoted easier and it makes economically feasible too. Tariffs vary widely, both below and above the national average price for grid electricity of $11 \phi / \mathrm{kWh}$;

- The productive use of hydro-electricity is still minimal. One of the reasons was NSP's focus to promote rural electrification mainly for lighting purpose. Very small generation capacity of the majority of the power plants as well as single-phase under-voltage power supply could be some of the other reasons behind it. The awareness campaigns on the productive use of electricity as well as 
the support for the establishment of marketing mechanism of locally produced goods could help to increase the productive users in the future;

- The portion of the end user that is not satisfied with the supply of electricity is relatively low. This dissatisfaction could be largely eliminated if the operators at the respective sites are provided with a basic training about the repair maintenance of the MHP plants. This could at least help to repair some of the defects such as water leakage, small defects in generators and motors, etc. leading to the smooth operation of those plants,

- Depending upon the power generation potential at the specific site, as well as the electricity demand in its vicinity, some of the power plants could be upgraded to bigger sizes. The installation of larger capacity plants could reduce the initial investment cost per $\mathrm{kW}$ capacity. However, the management of such plants should be done in a professional way securing reliable and high quality power supply necessary for productive use. The realization of such projects needs further studies on individual site. For this, the first steps would be the identification of potential sites where the power output can be increased and the estimation of the rehabilitation costs. Although it depends on the surplus electricity generation at individual power plants as well as the period (hours of the day) of consumption in different villages, a study on the possibility of micro grid establishment in the province could be useful. Such a grid would not only maximize the electricity utilization as a whole, but also help to improve the power quality (better voltage stability). However, economic and political aspects of such micro grid formation should be analysed for the sustainability of such projects;

- There is no doubt that the end users in those Afghan villages are enjoying the common benefits of electrification similar to elsewhere: electricity for lighting, for communication devices (mobile charging, television, radio, etc.), and sometimes for other appliances and machinery (ironing, rice cooker, oil extraction machine operation, grains grinding, etc.). Other benefits include the village-street lighting, children's home study in the evening, less/no health hazards by avoiding the use of kerosene lamps, etc. However, under the scope of this study, these benefits are not surveyed and quantified.

\section{CONCLUSIONS}

In Badakhshan, 173 MHP plants were surveyed with a total installed capacity of 5.18 MW connecting about $15 \%$ of the total population in the province. The majority of MHPs (165) operate with capacities of far less than $100 \mathrm{~kW}$. From the total installed capacity, only $57 \%$ of capacity (2.94 MW) was operational during the time of the survey. In Baghlan, the total installed capacity of the operational power plants was about $585 \mathrm{~kW}$ (in 40 sites) and about $225 \mathrm{~kW}$ was under construction (in 16 sites). The capacity in individual site varied from 5 to $30 \mathrm{~kW}$. The investment cost for these power plants was quite high, i.e. about $83 \%$ of the installed capacity was more expensive than 2,500 USD/kW. In Balkh, the total installed capacity of the operational power plants was about $244 \mathrm{~kW}$ (in 13 sites). The capacity in individual site varied from 10 to $48 \mathrm{~kW}$. In Takhar, if almost all of these MHPs would generate electricity to their design capacity, only about $17 \%$ of the province's population could have access to the electricity. The total installed capacity of MHP plants for 160 sites was about 4.4 MW. The installed capacity for individual plants varied between 4 and $152 \mathrm{~kW}$.

The non-operating capacities in different provinces varied; the highest being in Badakhshan province, i.e. $43 \%$. The same rate for Takhar province was only $10 \%$. For Baghlan and Balkh, the operational rate is close to $100 \%$. Theoretically, the rehabilitation 
or only repair-maintenance of non-operating capacity should be possible to bring them back to their normal operation. However, individual site specific studies are necessary for exact recommendations. Upon the complete rehabilitation of non-operating power plants (i.e. assuming $100 \%$ of the installed capacity being operational) the number of people that could be supplied with MHP electricity in four provinces would be about 380,000 i.e., $10 \%$ of the total population of those four provinces.

Based on the summarized points above, we conclude that the rural electrification is important in Afghan villages, but it can contribute to the local socio-economic development effectively only when the use of electricity is expanded beyond mere lighting to entrepreneurial uses. This ensures also the techno-economical sustainability of rural electrification projects.

\section{ACKNOWLEDGEMENT}

Authors would like to thank GIZ ESRA (then GTZ ESRA) programme for making the MHP plants field survey data available for the analysis. Parts of the results (only for Takhar province) were published in a GTZ ESRA internal report, which was written by the corresponding author of this paper.

\section{REFERENCES}

1. Aqeel, A. and Butt, M. S., The Relationship between Energy Consumption and Economic Growth in Pakistan, Asia-Pacific Development Journal, Vol. 8, No. 2, pp 101-110, 2001.

2. Kraft, J. and Kraft, A., On the Relationship between Energy and GNP, Journal of Energy and Development, Vol. 3, pp 401-403, 1978.

3. Lee, C.-C. and Chang, C.-P., Energy Consumption and Economic Growth in Asian Economies: A more Comprehensive Analysis using Panel Data, Resource and Energy Economics, Vol. 30, No. 1, pp 50-65, 2008, http://dx.doi.org/10.1016/j.reseneeco.2007.03.003

4. Nexant, Subsidizing Rural Electrification in South Asia: An Introductory Guide, USAID SARI Energy Programme, 2004.

5. AEIC (Afghan Energy Information Centre), National Status Report - Generation, AEIC: Kabul, 2010.

6. AEIC (Afghan Energy Information Centre), Annual Electricity Production Report 2010, AEIC: Kabul, 2011.

7. AEIC (Afghan Energy Information Centre), Annual production report - 2011, AEIC: Kabul, Afghanistan, 2012.

8. CSO, Population Database for Afghanistan (2009-10), CSO: Kabul, 2010.

9. CIA, CIA World Fact Book - Afghanistan, https://www.cia.gov/library/publications/the-world-factbook/geos/af.html, [Accessed: April-2013]

10.DABS (Da Afghanestan Breshna Sherkat), DABS Customer Database 2010, DABS: Kabul, 2011.

11. GTZ ESRA, Energieprogramm Afghanistan - Internal Reports, GTZ ESRA: Kabul, Afghanistan, 2010.

12. Mainali, B. and Silveira, S., Financing Off-grid Rural Electrification: Country Case Nepal, Energy, Vol. 36, No. 4, pp 2194-2201, 2011, http://dx.doi.org/10.1016/j.energy.2010.07.004

13.Pigaht, M. and van der Plas, R. J., Innovative Private Micro-hydro Power development in Rwanda, Energy Policy, Vol. 37, No. 11, pp 4753-4760, 2009, http://dx.doi.org/10.1016/j.enpol.2009.06.039 
14. NSP (National Solidarity Programme), National Solidarity Programme - Afghanistan, http://www.nspafghanistan.org/, [Accessed: November-2012]

15. Shoaib, A., Rural development in Afghanistan: The Impact of Renewable Energy, Willy Brandt School of Public Policy, University of Erfurt: Erfurt, Germany, 2011.

16.NSP (National Solidarity Programme), NSP Operational Manual, http://www.nspafghanistan.org/default.aspx?sel=16, [Accessed: November-2012]

17. NSP (National Solidarity Programme), Database on NSP Implemented Projects - An Internal Report, NSP: Kabul, 2011.

18. Nexant, MHP assessment for USAID, Nexant/USAID, 2006.

19.Xe, Xe Currency Converter, http://www.xe.com/ucc/full/, [Accessed: May-2013]

20. GTZ ESRA, Afghanistan Rural Renewable Energy Strategy, GTZ ESRA: Kabul, Afghanistan, 2010.

21. Mainali, B. and Silveira, S., Alternative Pathways for Providing Access to Electricity in Developing Countries, Renewable Energy, Vol. 57, No. 0, pp 299-310, 2013, http://dx.doi.org/10.1016/j.renene.2013.01.057 